\title{
Vagal stimulation and its role in eliciting gastrin but not glucagon release from the isolated perfused dog stomach $^{1}$
}

\author{
P. J. LEFEBVRE, ${ }^{2}$ A. S. LUYCKX, AND A. H. BRASSINNE \\ From the Institute of Medicine, University of Liège, Liège, Belgium
}

SUMMARY Electrical stimulation $(10 \mathrm{~V}, 10 \mathrm{~Hz}, 3 \mathrm{~min})$ of both dorsal and ventral vagal trunks of the isolated canine stomach perfused with whole blood induced strong gastric contractions, transient release of cyclic GMP and marked release of gastrin. No gastric-glucagon release was elicited either at 'normal' $(4.8 \pm 0.1 \mathrm{mmol} / \mathrm{l})$ or at low $(1.5 \pm 0.1 \mathrm{mmol} / \mathrm{l})$ concentrations of blood glucose. It is concluded that, in conditions effective for the stimulation of gastrin release, electrical stimulation of the vagus nerves does not stimulate glucagon release from the isolated perfused dog stomach. Thus one of the well-accepted mechanisms controlling pancreatic-glucagon secretion, vagal stimulation, is ineffective on gastric-glucagon release.

The isolated perfused dog stomach provides a useful tool for the in vitro study of the mechanisms controlling gastric hormone release (Lefebvre et al., 1976; Lefebvre and Luyckx, 1976, 1977). Recent in vivo and in vitro experiments have demonstrated that gastric-glucagon release was stimulated by intra-arterial (Lefebvre and Luyckx, 1976, 1977; Muñoz-Barragan et al., 1976) or intraluminal (Muñoz-Barragan et al., 1976) arginine, and by insulin deprivation (Blazquez et al., 1976; Vranic et al., 1976a). On the other hand arginine-induced gastric-glucagon release is inhibited by somatostatin (Dobbs et al., 1975; Lefebvre and Luyckx, 1976, 1977); it is not affected by hyperglycaemia alone but is reduced by about $40 \%$ when hyperglycaemia is concomitant with a hyperinsulinaemia within the physiological range (Lefebvre and Luyckx, 1976, 1977). As demonstrated by other investigators (Bloom et al., 1973, 1974a, b; Kaneto et al.,

\footnotetext{
${ }^{1}$ Supported in part by the Fonds National de la Recherche Scientifique and the Fonds de la Recherche Scientifique Médicale of Belgium. Dr Luyckx is Established Investigator of the FNRS.

2Address for reprint requests: Dr $P$. Lefebvre, Division of Diabetes, University of Liège, Hôpital de Bavière, Blv. de la Constitution, 66 B-4020 Liège, Belgique.
}

Received for publication 13 September 1977
1974), pancreatic glucagon secretion is increased in response to vagal stimulation. The aim of the present study was to investigate the effect of an electrical stimulation of the vagus nerves on the release of glucagon from the isolated perfused dog stomach. In view of the well-known effect of blood glucose on glucagon secretion (Review in Unger and Lefebvre, 1972), the experiments were performed both at normal and low glucose concentrations of the perfusing blood. The release of gastrin, which is known to be under vagal control was simultaneously evaluated. As there is evidence that cholinergic stimulation might be associated with an increased intracellular accumulation and extracellular release of guanosine-3', $5^{\prime}$ adenosine monophosphate (cyclic GMP) (Butcher et al., 1976), the net gastric output of this nucleotide was also measured.

\section{Methods}

The stomachs of overnight-fasted $9 \cdot 5-12 \mathrm{~kg}$ dogs of both sexes were isolated according to a procedure previously described by Lefebvre and Luyckx (1977) with, in addition, careful dissection and isolation of both dorsal and ventral vagal trunks along the oesophagus to a distance of about $5 \mathrm{~cm}$ from the cardia. The isolated stomachs were perfused with whole canine blood supplemented with Trasylol (Bayer, Leverkusen, Germany) as previously described (Lefebvre and Luyckx, 1977). In four experi- 
ments, the blood perfusing each stomach was supplemented with a glucose solution $(10 \% \mathrm{~W} / \mathrm{V})$ in order to maintain a 'normal' blood glucose concentration (about $4.7 \mathrm{mmol} / 1$ or $85 \mathrm{mg} \%$ ), while, in four other experiments, no glucose was added, thus permitting the blood glucose concentration to fall during the equilibration period, because of consumption of glucose by stomach and blood cells. After a 50-60 minute equilibration period during which the blood was recirculated, blood samples were collected continuously from the vein at intervals of 10-30 seconds, without recirculation of the blood before, during, and after an electrical stimulation of both vagal trunks. Two arterial blood samples were collected before and after the electrical stimulation. The electrical stimulation was performed for three minutes, at an amplitude of $10 \mathrm{~V}$ and a frequency of $10 \mathrm{~Hz}$ using Tektronix Pulse Generators (Types 162 and 163, Tektronix, Inc, Portland, Oregon, USA). Arterial blood glucose concentration was determined using the method of Hoffman (1937) adapted to the Technicon Auto-Analyzer. For hormone assays, 0.4 $\mathrm{ml}$ of a solution containing Trasylol, $5000 \mathrm{U} / \mathrm{ml}$, and $\mathrm{Na}_{2}$ EDTA, $12 \mathrm{mg} / \mathrm{ml}$, were added to $3.6 \mathrm{ml}$ of blood. The mixture was immediately centrifuged at $+4^{\circ} \mathrm{C}$ and the separated plasma was stored at $-20^{\circ} \mathrm{C}$. Plasma glucagon was determined in duplicate assays by an established radioimmunoassay procedure (Luyckx, 1972), using porcine ${ }^{125}$ I-labelled-glucagon as tracer, $30 \mathrm{~K}$ antiserum (provided by $\mathrm{Dr} \mathbf{R} . \mathbf{H}$. Unger, Dallas), and a dextran-charcoal separation of free and antibody-bound hormone. Plasma gastrin was assayed in duplicate by radioimmunoassay using a commercial kit (Gask, Institut National des Radioéléments, Fleurus, Belgium); human gastrin 1-17 was used as standard and ${ }^{125}$ I-labelled human gastrin as tracer; an anti-human gastrin was used as antibody and the separation of free and antibodylabelled hormone was performed using dextrancharcoal. The identity of reactivity between dog and human gastrin was assayed by verifying the parallelism of dilution curves. Plasma insulin was determined as previously described (Quabbe, 1969; Lefebvre and Luyckx, 1972). For cyclic GMP assay $10 \mu \mathrm{l} \mathrm{Na} 2$ EDTA $0.5 \mathrm{M}$ were added to $1 \mathrm{ml}$ blood. After centrifugation, plasma cyclic GMP was assayed by radioimmunoassay (cyclic GMP/RIA kit, the Radiochemical Center, Amersham, England). Gastric-glucagon, gastrin, and cyclic-GMP production by the stomach were calculated by multiplying the venoarterial difference in their plasma concentrations by the plasma flow (the latter being derived from the blood flow and the haematocrit). Statistical analysis was performed using Student's $t$ test for paired and non-paired data.
Results

PERFUSING CONDITIONS AND BASAL VALUES The haemoglobin $\mathrm{O}_{2}$ saturation of the perfusing blood remained over $98 \%$ throughout the experiment and the stomach produced $18.9 \pm 4.2 \mathrm{ml} / \mathrm{h} / 100 \mathrm{~g}$ of stomach of an acidic juice ( $\mathrm{pH} 4.4 \pm 0.9)$ during the equilibration period. Arterial blood glucose was $4.8 \pm 0.1 \mathrm{mmol} / 1$ or $86 \pm 2 \mathrm{mg} \%(\mathrm{n}=4)$ in the 'normal glucose' experiments and $1.5 \pm 0.1 \mathrm{mmol} / \mathrm{l}$ or $27 \pm 2 \mathrm{mg} \%(\mathrm{n}=4)$ in the 'low glucose' experiments. Plasma glucagon and gastrin concentrations in the perfusing blood, before the introduction of the stomach in the circuit, averaged $126 \pm 19$ and $11 \pm 3 \mathrm{pg} / \mathrm{ml}(\mathrm{n}=8)$, respectively. Basal plasma insulin was $3.7 \pm 0.7 \mu \mathrm{U} / \mathrm{ml}(\mathrm{n}=8)$. Basal gastric blood flow was $77 \pm 3 \mathrm{ml} / \mathrm{min} / 100 \mathrm{~g}$ of stomach. Basal gastric-glucagon release was not statistically different from zero at both normal or low blood glucose concentration. Basal gastrin release was similar at normal and low blood glucose concentration and averaged $134 \pm 31 \mathrm{pg} / \mathrm{min} / 100 \mathrm{~g}$ stomach, a value significantly different from zero $(P<0.01)$. Basal cyclic GMP output averaged $9.2 \pm 8.0 \mathrm{pmol} / \mathrm{min} / 100 \mathrm{~g}$, a value not statistically different from zero.

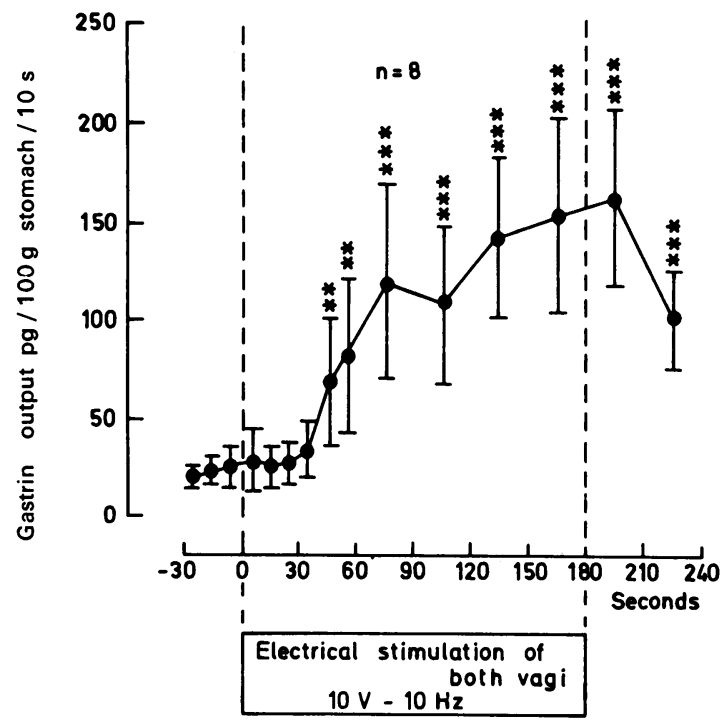

Fig. 1 Effect of the electrical stimulation of the dorsal and ventral vagal trunks on gastrin release from the isolated perfused dog stomach. The results of the experiments are grouped, as no difference was observed in the gastrin response between the 'normal' and the 'low' blood glucose experiments. Results are expressed as mean \pm SEM. $\mathrm{P}<0.02\left({ }^{* *}\right)$ and $<0.01\left({ }^{* * *}\right)$ versus prestimulation values. 
ELECTRICAL STIMULATION OF THE VAGUS NER VES

The electrical stimulation of both dorsal and ventral vagal trunks for three minutes induced violent contractions of the gastric musculature, the gastric blood flow remaining unchanged. It induced a transient release of cyclic GMP: $19.7 \pm 8.5 \mathrm{pmol} /$ $\mathrm{min} / 100 \mathrm{~g}$ during the first minute of stimulation. As shown in Fig. 1, electrical stimulation of both vagi markedly stimulated gastrin release. The first significant rise was detected 40-50 seconds after the beginning of the stimulation, the release remained high up to the end of the stimulation and started to decline 30-60 seconds later. In contrast (Fig. 2), the electrical stimulation of the vagus nerves did not elicit any change in gastric-glucagon release either at 'normal' or at 'low' blood glucose concentrations.

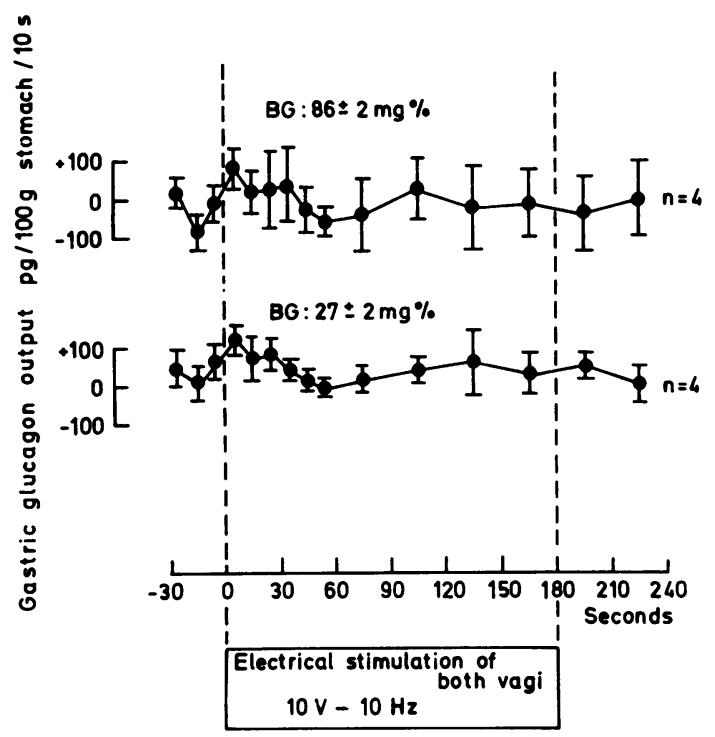

Fig. 2 Lack of modification of gastric-glucagon release in response to the electrical stimulation of the dorsal and ventral vagal trunks of the isolated perfused dog stomach. Four stimulations were effected at 'normal' and 'low' blood glucose $(B G)$ concentrations.

\section{Discussion}

Several groups recently reported the presence in the gastrointestinal tract of a material identical by all criteria to pancreatic glucagon (Sasaki et al., 1975; Holst, 1977) as well as the presence of 'true A cells' in the dog gastric fundus (Baetens et al., 1976). The isolated perfused dog stomach provides a useful tool for studying gastric-glucagon release in an animal species where the quantity of this polypeptide in the stomach is particularly abundant (Morita et al., 1976). Until now, data have been available only on the metabolic or hormonal factors modifying gastric-glucagon release (Dobbs et al., 1975; Muñoz-Barragan et al., 1976; Lefebvre et al., 1976; Lefebvre and Luyckx, 1976, 1977). The present investigation aimed to determine whether or not vagal stimulation, a well-known stimulus of pancreatic glucagon secretion (Kaneto et al., 1974; review in Bloom, 1976), also stimulated the release of glucagon from the stomach. In our experimental conditions the efficiency of the vagal stimulation was attested by (1) the induction of visible gastric contractions, (2) a transient release of cyclic GMP, a phenomenon usually associated with cholinergic stimulation (Butcher et al., 1976), and, mainly, (3) an unequivocal release of gastrin. Under these conditions of effective stimulation of the vagus nerves, no release of glucagon by the stomach was observed. This was true even at low glucose concentrations and in the presence of extremely low circulating concentrations of insulin. We, therefore, conclude that gastric-glucagon secretion in the dog, contrary to pancreatic glucagon secretion (Bloom et al., 1973, 1974a, b), is not under the control of the parasympathetic nervous system. This suggests that gastric-glucagon secretion is more dependent on metabolic or hormonal control rather than on neural factors. Vranic et al. (1976b) have indeed observed that strenuous exercise, which is known to be a potent stimulus of pancreatic-glucagon secretion probably mainly through stimulation of the adrenergic system (Luyckx and Lefebvre, 1974; Luyckx et al., 1975), does not induce any rise in the plasma glucagon levels of depancreatised dogs, a situation in which circulating glucagon is known to be essentially of gastric origin.

We thank Dr M. Tunbridge for his help during the preparation of this manuscript. We acknowledge the technical assistance of Mr and Mrs Thoumsin and Miss A. Rombaux and the secretarial assistance of Mrs E. Vaessen-Petit. We are indebted to Professor A. Nizet and Professor A. Dresse for providing laboratory and material facilities.

\section{References}

Baetens, D., Rufener, C., Srikant, C. B., Dobbs, R., Unger, R., and Orci, L. (1976). Identification of glucagonproducing cells (A cells) in dog gastric mucosa. Journal of Cell Biology, 69, 455-464.

Blazquez, E., Muñoz-Barragan, L., Patton, G. S., Orci, L., Dobbs, R. E., and Unger, R. H. (1976). Gastric A-cell function in insulin-deprived depancreatized dogs. Endocrinology, 99, 1182-1188. 
Bloom, S. R. (1976). Blood glucose control by direct islet innervation. In Hypoglycemia, pp. 85-90. Edited by D. Andreani, P. Lefebvre and V. Marks. Georg Thieme: Stuttgart.

Bloom, S. R., Edwards, A. V., and Vaughan, N. J. (1973). The role of the sympathetic innervation in the control of plasma glucagon concentrations in the calf. Journal of Physiology, 233, 457-466.

Bloom, S. R., Edwards, A. V., and Vaughan, N. J. (1974a). The role of the autonomic innervation in the control of glucagon release during hypoglycemia in the calf. Journal of Physiology, 236, 611-623.

Bloom, S. R., Vaughan, N. J. A., and Russell, R. C. G. (1974b). Vagal control of glucagon release in man. Lancet, 2, 546-549.

Butcher, F. R., McBride, P. A., and Rudich, L. (1976). Cholinergic regulation of cyclic nucleotide levels, amylase, and $\mathrm{K}^{+}$efflux from rat parotid glands. Molecular and Cellular Endocrinology, 5, 243-254.

Dobbs, R. E., Sakurai, H., Sasaki, H., Faloona, G. R., Valverde, I., Baetens, D., Orci, L., and Unger, R. H. (1975). Glucagon: role in the hyperglycemia of diabetes mellitus. Science, 187, 544-547.

Hoffman, W. S. (1937). A rapid photoelectric method for the determination of glucose in blood and urine. Journal of Biological Chemistry, 120, 51-55.

Holst, J. J. (1977). Extraction, gel filtration pattern, and receptor binding of porcine gastrointestinal glucagon-like immunoreactivity. Diabetologia, 13, 159-169.

Lefebvre, P. J., and Luyckx, A. S. (1972). Effect of ouabain on insulin secretion in the anesthetized dog. Biochemical Pharmacology, 21, 339-345.

Lefebvre, P. J., and Luyckx, A. S. (1976). Control of gastric glucagon secretion (Abstract). Diabetologia, 12, 405.

Lefebvre, P. J., and Luyckx, A. S. (1977). Factors controlling gastric-glucagon release. Journal of Clinical Investigation, 59, 716-722.

Lefebvre, P. J., Luyckx, A. S., Brassinne, A. H., and Nizet, A. H. (1976). Glucagon and gastrin release by the isolated perfused dog stomach in response to arginine. Metabolism, 25. suppl. 1, 1477-1479.

Luyckx, A. S. (1972). Immunoassays for glucagon. In Glucagon, Molecular Physiology, Clinical and Therapeutic Implications, pp. 285-298. Edited by P. J. Lefebvre and R. H. Unger. Pergamon Press: Oxford.

Luyckx, A. S., Dresse, A., Cession-Fossion, A., and Lefebvre, P. J. (1975). Role of catecholamines in exercise-induced glucagon secretion and free fatty acid mobilization in rats. American Journal of Physiology, 229, 376-383.

Luyckx, A. S., and Lefebvre, P. J. (1974). Mechanisms involved in the exercise-induced increase in glucagon secretion in rats. Diabetes, 23, 81-93.

Morita, S., Doi, K., Yip, C., and Vranic, M. (1976). Measurements and partial characterization of immunoreactive glucagon in gastro-intestinal tissues of dogs. Diabetes, 25, 1018-1025.

Muñoz-Barragan, L., Blazquez, E., Patton, G. S., Dobbs, R. E., and Unger, R. H. (1976). Gastric A-cell function in normal dogs. American Journal of Physiology, 231, 1057-1061.

Quabbe, H.J.(1969). Modifikation der radioimmunologischen insulinbestimmung nach Hales und Randle. Diabetologia, 5, 101-107.

Sasaki, H., Rubalcalva, B., Baetens, D., Blazquez, E., Srikant, C. B., Orci, L., and Unger, R. H. (1975). Identification of glucagon in the gastrointestinal tract. Journal of Clinical Investigation, 56, 135-145.

Unger, R. H., and Lefebvre, P. J. (1972). Glucagon physiology. In Glucagon, Molecular Physiology, Clinical and Therapeutic Implications, pp. 213-244. Edited by P. J. Lefebvre and R. H. Unger. Pergamon Press: Oxford.

Vranic, M., Engerman, R., Doi, K., Morita, S., and Yip, C. (1976a). Extrapancreatic glucagon in the dog. Metabolism, 25, suppl. 1, 1469-1473.

Vranic, M., Kawamori, R., Pek, S., Kovasevic, N., and Wrenshall, G. A. (1976b). The essentiallity of insulin and the role of glucagon in regulating glucose utilization and production during strenuous exercise in dogs. Journal of Clinical Investigation, 57, 245-255. 